\title{
Postsurgical pain is attenuated in men with elevated presurgical systolic blood pressure
}

\author{
Christopher R France $\mathrm{PhD}^{1}$, Joel Katz $\mathrm{PhD}^{2}$
}

\begin{abstract}
CR France, J Katz.
Postsurgical pain is attenuated in men with elevated presurgical systolic blood pressure.

Pain Res Manage 1999;4(2):100-103.

Previous research has demonstrated that elevated resting blood pressure is associated with a decreased perception of experimental pain. To assess this relationship in the context of clinical pain, postsurgical pain ratings were obtained from 159 men recovering from radical prostatectomy. Participants ranged in age from 46 to 75 years (Mean=61.9, $\mathrm{SD}=5.9)$, and on admission to the hospital had mean systolic and diastolic blood pressures of 134.2/79.9 $\mathrm{mmHg}$ $(\mathrm{SD}=19.2 / 10.2)$. Pain ratings were obtained at $24 \mathrm{~h}$ and $48 \mathrm{~h}$ postsurgery using the McGill Pain Questionnaire and Visual Analog Scales administered at rest and after standardized movement (VAS-M). Results of correlational analyses indicated that higher preoperative resting systolic blood pressure was associated with significantly lower VAS-M pain ratings at $24 \mathrm{~h}$ postsurgery and significantly lower ratings on all pain measures at $48 \mathrm{~h}$ postsurgery. The relationships between blood pressure and pain ratings were maintained even after controlling for individual differences in age, length of surgery and postsurgical self-administration of morphine. These results confirm and extend previous observations of decreased pain in individuals with elevated blood pressure and suggest that this effect persists despite access to morphine analgesia.
\end{abstract}

Key Words: High blood pressure; Pain; Prostatectomy; Surgery
Diminution de la douleur postopératoire chez les hommes présentant une tension artérielle systolique élevée en phase préopératoire

RÉSUMÉ :Des recherches ont déjà montré qu'une tension artérielle élevée au repos est associée à une diminution de la perception de la douleur. Afin de vérifier ce lien dans un contexte de douleur clinique, des chercheurs ont demandé à 159 hommes ayant subi une prostatectomie radicale d'évaluer leur douleur en phase postopératoire. L'âge des patients variait entre 46 et 75 ans (moyenne : 61,9 ; écart type : 5,9) et leur tension artérielle systolique et diastolique moyenne au moment de l'admission à l'hôpital était de 134,2/79,9 mmHg (écart type : 19,2/10,2). L'évaluation de la douleur s'est faite $24 \mathrm{~h}$ et $48 \mathrm{~h}$ après l'opération, au repos et après l'exécution d'un mouvement normalisé (VAS-M), à l'aide du questionnaire de McGill sur la douleur et d'une échelle analogique visuelle. Les résultats de l'analyse corrélationnelle indiquent qu'une tension artérielle systolique élevée au repos en phase préopératoire est associée à une évaluation passablement plus faible de la douleur sur l'échelle VAS-M 24 h après l'intervention et à une évaluation passablement plus faible de la douleur pour toutes les mesures de la douleur prises $48 \mathrm{~h}$ après l'opération. Le rapport entre la tension artérielle et l'évaluation de la douleur s'est maintenu même après correction pour l'âge, la durée de l'intervention et l'auto-administration de morphine en phase postopératoire. Les résultats confirment et dépassent même les observations faites antérieurement sur la diminution de la douleur chez les patients présentant une tension artérielle élevée et donnent à penser que l'effet persiste malgré l'administration de morphine.
Cor almost two decades, researchers have demonstrated a reliable relationship between elevated resting blood pressure and increased experimental pain thresholds. In laboratory animal studies, elevated blood pressure levels have been associated with increased nociceptive thresholds in hot-plate (1-4), tail-flick (1,5) and flinch-jump (3) paradigms. In humans, hypertension is consistently associated with decreased pain in response to electrical tooth pulp stimulation (6-9),

\footnotetext{
${ }^{1}$ Department of Psychology, Ohio University, Athens, Ohio, USA; ${ }^{2}$ Department of Psychology, The Toronto Hospital

Acute Pain Research Unit, Department of Anaesthesia, The Toronto Hospital and Mount Sinai Hospital Department of Public Health Sciences and Department of Anaesthesia, University of Toronto, Toronto, Ontario

Correspondence and reprints: Christopher France, Department of Psychology, Ohio University, 245 Porter Hall, Athens, Ohio 45701, USA. Telephone 740-593-1079, fax 740-593-0579, e-mail France@ohiou.edu.
} 
TABLE 1

Mean and standard deviation of visual analog scales (VAS) and McGill Pain Questionnaire (MPQ) pain ratings following prostatectomy surgery

\begin{tabular}{lccccccccc}
\hline & \multicolumn{4}{c}{ VAS } & \multicolumn{4}{c}{ MPQ } \\
& \multicolumn{2}{c}{ Rest } & \multicolumn{3}{c}{ Movement } & \multicolumn{2}{c}{ T-PRI } & \multicolumn{2}{c}{ PPI } \\
Time & Mean & SD & Mean & SD & Mean & SD & Mean & SD \\
\hline $\begin{array}{c}24 \text { h after } \\
\text { surgery }\end{array}$ & $1.9^{*}$ & 1.7 & $5.3^{*}$ & 2.4 & $11.1^{*}$ & 10.5 & 1.4 & 0.9 \\
$\begin{array}{c}48 \text { h after } \\
\text { surgery }\end{array}$ & 1.4 & 1.9 & 4.3 & 2.4 & 7.7 & 9.2 & 1.2 & 1.2 \\
\hline
\end{tabular}

*A significantly higher value at $24 h$ versus $48 h$ postsurgery $(P<0.05)$. PPI Present Pain Intensity scale; T-PRI Total Pain Rating Index

cutaneous heat $(10,11)$ and mechanical pinching of skin folds (12). Studies of individuals with normal blood pressure also indicate an inverse relationship between blood pressure levels and pain responses to electrocutaneous stimulation $(13,14)$, finger pressure $(15,16)$, cold pressor applied to the hand (17), heat applied to the arm (18) and tourniquet forearm ischemia (18).

In contrast, with the increasing evidence of an association between high blood pressure and decreased experimental pain, there is only limited and indirect evidence of this relationship in the context of clinical pain. For example, individuals with hypertension are more likely to experience silent ischemia during exercise testing $(19,20)$, suggesting that high blood pressure may mask the symptom of chest pain that often accompanies myocardial ischemia. Consistent with this finding, data from the Framingham Heart Study indicate that individuals with hypertension are nearly twice as likely to experience an unrecognized myocardial infarction as individuals with normal blood pressure (21). There is also some evidence that individuals with elevated blood pressure are less likely to report physical symptoms such as headaches (22). Because pain is a primary motivator for seeking medical attention, decreased pain perception among individuals with elevated blood pressure can lead to delays in seeking medical care that, as in the case of myocardial ischemia, may have serious health consequences.

In the present study, the relationship between resting systolic blood pressure and postsurgical pain ratings in men undergoing radical prostatectomy was examined. In addition to allowing us to reassess the relationship between blood pressure and pain in a clinical context, this design also provided a unique opportunity to examine this relationship in response to an invasive procedure that produced actual tissue damage. Further, because patients were given access to a patient-controlled analgesia (PCA) pump system during recovery, postoperative self-administration of morphine could also be used as an additional index of pain experience.

\section{PATIENTS AND METHODS}

Approval to carry out the study was obtained from the Toronto Hospital Committee for Research on Human Subjects. All patients gave their written informed consent to participate.

One hundred and fifty-nine men undergoing radical pros- tatectomy surgery for prostate cancer at the Toronto Hospital, Toronto, Ontario, participated. Participants ranged in age from 46 to 75 years $($ Mean $=61.9, S D=5.9)$, and had average resting systolic and diastolic blood pressures of 134.2/79.9 mmHg ( $\mathrm{SD}=19.2 / 10.2)$. Thirty-eight of the participants (24\%) had a previous diagnosis of hypertension, and 37 were taking medication to control their blood pressure. Prostatectomy surgery times ranged from 30 to 351 mins, with a mean duration of 188.7 mins $(\mathrm{SD}=38.9)$.

\section{PROCEDURE}

Upon admission to the hospital, participant vital signs were obtained by an admitting nurse and recorded in the patient chart. Resting blood pressure values used in this study were obtained during admission using a manual sphygmomanometer with the patient in a seated position.

One day before surgery, participants were familiarized with the postoperative pain scales and were introduced to the PCA pump and carefully instructed in its use. Following surgery, participants were transferred to the postanesthetic care unit and were connected to a PCA pump (Abbott Life Care Infuser, Chicago, Illinois). Every 10 mins, they were asked whether they were in need of pain relief. An affirmative response was followed by a $2 \mathrm{mg}$ intravenous bolus of morphine that was administered by a nurse. This procedure was repeated until the participants were sufficiently alert to begin using the pump on their own. The PCA pump was set to deliver a 1.5 to $2.0 \mathrm{mg}$ intravenous bolus dose of morphine with a lock-out time of 5 to 7 mins, a maximum dose of $30 \mathrm{mg}$ in any $4 \mathrm{~h}$ period and no continuous background infusion. This regimen was continued for up to $72 \mathrm{~h}$ postsurgery, during which time no other analgesics were administered. Morphine usage (in $\mathrm{mg}$ ) was calculated for each $24 \mathrm{~h}$ after surgery by using hard copy records.

Postoperative pain was assessed at $24 \mathrm{~h}$ and $48 \mathrm{~h}$ using a visual analog scale (VAS) with anchors of 0 (no pain) and 10 (worst possible pain). VAS ratings were obtained at rest and after a standardized movement that included sitting up from the lying position and performing two maximal inspirations using an incentive spirometer. Pain ratings were then obtained using the McGill Pain Questionnaire (MPQ) (23). Analyses of MPQ scores were conducted using the Present Pain Intensity and Total Pain Rating Index (T-PRI) scales.

\section{RESULTS}

\section{Descriptive statistics of postsurgical pain and medication use}

Means and SDs of participant pain ratings at $24 \mathrm{~h}$ and $48 \mathrm{~h}$ postsurgery are provided in Table $1 . t$ tests for paired samples indicated that participants reported significantly more pain at 24 versus $48 \mathrm{~h}$ on both VAS ratings, and on the MPQ and TPRI scales.

\section{Correlation analyses of blood pressure and postsurgical pain}

Pearson correlational analyses were conducted to assess the relationship between preoperative resting systolic blood 
TABLE 2

Correlations between resting systolic blood pressure and visual analog scale (VAS), and McGill Pain Questionnaire (MPQ) pain ratings following prostatectomy surgery

\begin{tabular}{lcccc}
\hline & \multicolumn{2}{c}{ VAS } & \multicolumn{2}{c}{ MPQ } \\
Time & Rest & Movement & T-PRI & PPI \\
\hline $\begin{array}{c}24 \text { h after } \\
\text { surgery }\end{array}$ & -0.02 & $-0.15^{*}$ & -0.02 & -0.03 \\
$\begin{array}{c}48 \text { h after } \\
\text { surgery }\end{array}$ & $-0.19^{*}$ & $-0.17^{*}$ & $-0.16^{*}$ & $-0.24^{*}$ \\
\hline
\end{tabular}

${ }^{*} P<0.05$, one-tailed. PPI Present Pain Intensity scale; T-PRI Total Pain Rating Index

pressure levels and pain ratings at $24 \mathrm{~h}$ and $48 \mathrm{~h}$ postsurgery. Given the hypothesized inverse relationship between blood pressure and pain, statistical significance was set at $=0.05$ for a one-tailed test. As can be seen in Table 2, at $24 \mathrm{~h}$ postsurgery there was a significant inverse relationship between preoperative resting systolic blood pressure and VAS pain ratings following movement. At $48 \mathrm{~h}$ postsurgery, higher systolic blood pressure was associated with significantly lower ratings on all pain measures. Similar results were obtained when the correlational analyses were restricted to participants who were not taking antihypertensive medication. Despite the observed relationship between blood pressure and subjective pain, preoperative systolic blood pressure was not significantly related to PCA dose at either $24 \mathrm{~h}$ postsurgery $(\mathrm{r}=-0.09)$ or $48 \mathrm{~h}$ postsurgery $(\mathrm{r}=-0.06)$.

\section{Partial correlations controlling for PCA, age and duration of surgery}

Because pain ratings were positively correlated with PCA self-administration at both $24 \mathrm{~h}$ and $48 \mathrm{~h}$ postsurgery $(\mathrm{r}=0.07$ to 0.22 ), the correlations between preoperative blood pressure and pain ratings were recalculated as partial correlations controlling PCA dose on each day. As can be seen in Table 3, these analyses yielded similar $r$ values and identical significance levels as those obtained without controlling for PCA dose, indicating that blood pressure was inversely related to pain regardless of the level of morphine that was selfadministered. Similar partial correlations controlling for participant age and duration of surgery also failed to alter significantly the observed inverse relationship between resting systolic blood pressure and postsurgical pain.

\section{DISCUSSION}

In agreement with previous laboratory pain studies, the results of the present investigation indicate that resting systolic blood pressure is inversely related to postsurgical pain ratings in men recovering from radical prostatectomy. Although the correlation coefficients observed in this study are more modest than those reported for experimental pain stimuli such as cold pressor $(15,17)$, thermal pain (10) and mechanical stimulation $(12,24)$, these differences may be related to the fact that postsurgical pain was reduced by morphine. Specifically, postsurgical pain ratings were lower than
TABLE 3

Partial correlations between resting systolic blood pressure, visual analog scale (VAS) and McGill Pain Questionnaire (MPQ) pain ratings following prostatectomy surgery, controlling for patient-controlled analgesia dose on each day

\begin{tabular}{lcccc}
\hline & \multicolumn{2}{c}{ VAS } & \multicolumn{2}{c}{ MPQ } \\
Time & Rest & Movement & T-PRI & PPI \\
\hline $\begin{array}{l}24 \mathrm{~h} \text { after } \\
\text { surgery }\end{array}$ & -0.00 & $-0.14^{*}$ & -0.01 & 0.05 \\
$\begin{array}{l}48 \text { h after } \\
\text { surgery }\end{array}$ & $-0.18^{*}$ & $-0.16^{*}$ & $-0.15^{*}$ & $-0.23^{*}$ \\
\hline
\end{tabular}

${ }^{*} P<0.05$, one-tailed. PPI Present Pain Intensity scale; T-PRI Total Pain Rating Index

those typically reported for acute laboratory pain (17,25-27), suggesting that a restricted range of pain ratings may account for the more modest correlations observed between blood pressure and postsurgical pain. Differences in the subjective experience of postoperative versus acute laboratory pain may also affect the observed blood pressure and pain relationship because prostatectomy is likely to elicit a greater range and/or intensity of cognitive and emotional reactions that can contribute to variability in pain ratings. In any case, an important implication of the present finding is that hypoalgesia in individuals with high blood pressure extends beyond controlled laboratory environments; therefore, hypoalgesia may have consequences in the everyday lives of people with hypertension.

Naloxone has been shown to reverse hypoalgesia in hypertensive rats $(1,3,5)$, suggesting that decreased pain in hypertensive patients is mediated by enhanced endogenous opiate activity. There is also some evidence that hypertensive humans exhibit enhanced endogenous opiate activity $(11,28)$. The presence of elevated endogenous opiate levels among those with high blood pressure may be associated with a decreased need for exogenous opiates (eg, PCA) during recovery from surgery. Alternatively, tonic exposure to elevated endogenous opiate levels may lead to tolerance to their pain-reducing effects. Combined with the fact that morphine administration may suppress endogenous opiate release, it is also reasonable to hypothesize that individuals with high blood pressure may require higher PCA doses. In contrast with each of these hypotheses, the results of the present study indicate that there was no significant relationship between resting systolic blood pressure levels and PCA use, and that pain was inversely related to blood pressure even after controlling for PCA dose. These findings are in agreement with recent evidence that decreased pain perception in hypertensive humans may be mediated, at least in part, by nonopiate mechanisms (24). For example, it has been proposed that hypertensive patients exhibit enhanced activation of central pain modulation $(12,29)$, an effect that may or may not involve endogenous opiates.

Although the present findings provide important information concerning the relationship between blood pressure and clinical pain, there are several limitations. First, because our sample was restricted to men undergoing prostatectomy, our 
findings may not generalize to clinical pain in women. Despite existing evidence of an inverse relationship between resting systolic blood pressure and experimental pain in women $(14,30)$, additional research is required to assess this phenomenon outside of the laboratory. A second limitation is that we did not assess past experience with surgical pain; therefore, we could not evaluate this individual difference variable as a potential contributor to pain ratings during recovery from prostatectomy. Finally, preoperative resting blood pressure values were obtained from patient records collected at the time of admission to the hospital. As a result, our measure of systolic blood pressure is limited in that it was based on a single reading, it was obtained using a manual sphygmomanometer and it was collected at a time when patients may have been experiencing anticipatory anxiety. Given these potential limits on the reliability of the blood

\section{REFERENCES}

1. Wendel O, Bennett B. The occurrence of analgesia in an animal model of hypertension. Life Sci 1981;29:515-21.

2. Maixner W, Touw K, Brody M, Gebhart G, Long J. Factors influencing the altered pain perception in the spontaneously hypertensive rat. Brain Res 1982;237: 37-45.

3. Sitsen J, deJong W. Hypoalgesia in genetically hypertensive rats (SHR) is absent in rats with experimental hypertension. Hypertension 1983;5:185-90.

4. Tsai C, Lin M. Pain sensitivity, thermal capability, and brain monoamine turnover in hypertensive rats. Am J Physiol 1987;253:R910-6.

5. Saavedra J. Naloxone reversible decrease in pain sensitivity in young and adult spontaneously hypertensive rats. Brain Res 1981;209:245-9.

6. Zamir N, Shuber E. Altered pain perception in hypertensive humans. Brain Res 1980;201:471-4.

7. Rosa C, Ghione S, Panattoni E, Mezzasalma L, Guiliano G. Comparison of pain perception in normotensives and borderline hypertensives by means of a tooth pulp stimulation test. J Cardiovasc Pharmacol 1986;8:S125-7.

8. Ghione S, Rosa C, Mezzasalma L, Panattoni E. Arterial hypertension is associated with hypalgesia in humans. Hypertension 1988;12:491-7.

9. Guasti L, Rossana C, Rinaldi O, et al. Twenty-four-hour noninvasive blood pressure monitoring and pain perception. Hypertension 1995;25:1301-5.

10. Rau H, Brody S, Larbig W, et al. Effects of PRES baroreceptor stimulation on thermal and mechanical pain threshold in borderline hypertensives and normotensives. Psychophysiology 1994;31:480-5.

11. Sheps D, Bragdon E, Gray T, Ballenger M, Usedom J, Maixner W. Relation between systemic hypertension and pain perception. Am J Cardiol 1992;70:3F-5F.

12. Schobel HP, Ringkamp M, Behrmann A, Forster C, Schmieder RE, Handwerker HO. Hemodynamic and sympathetic nerve responses to painful stimuli in normotensive and borderline hypertensive subjects. Pain 1996;66:117-24.

13. Elbert T, Rockstroh B, Lutzenberger W, Kessler M, Pietrowsky R, Birbaumer N. Baroreceptor stimulation alters pain sensation depending on tonic blood pressure. Psychophysiology 1988;25:25-9.

14. Page GD, France CR. Objective evidence of decreased pain perception in normotensives at risk for hypertension. Pain 1997;73:173-80.

15. Bruehl S, Carlson C, McCubbin J. The relationship between pain sensitivity and blood pressure in normotensives. Pain 1992;48:463-7.

16. Ditto B, Seguin JR, Boulerice B, Pihl RO, Tremblay RE. Risk for pressure measurement, it is perhaps even more impressive that we were able to replicate the blood pressure and pain relationship previously observed under controlled laboratory conditions. Nonetheless, future studies are required to replicate and extend our findings using more diverse samples of participants, repeated assessments of resting blood pressure and a greater range of naturally occurring noxious events.

ACKNOWLEDGEMENTS: The authors thank Dawn McCoy, Keitha McMurray, Tanya Wiazek and Adarose Wowk for their help in data collection and entry. This work was supported by grant MT \#12052 from the Medical Research Council of Canada (MRC) and an MRC Scholar Award to Joel Katz, and by a grant from the American Heart Association, Ohio-West Virginia Affiliate, Columbus, Ohio awarded to Christopher France.

hypertension and pain sensitivity in adolescent boys. Health Psychol 1998;17:249-54.

17. McCubbin J, Bruehl S. Do endogenous opioids mediate the relationship between blood pressure and pain sensitivity in normotensives? Pain 1994;57:63-7.

18. Fillingim RB, Maixner W. The influence of resting blood pressure and gender on pain responses. Psychosom Med 1996;58:326-32.

19. Krittayaphong R, Sheps DS. Relation between resting blood pressure and perception of angina during exercise testing. Am J Cardiol 1996;77:1224-6.

20. Falcone C, Auguadro C, Sconocchia R, Angoli L. Susceptibility to pain in hypertensive and normotensive patients with coronary artery disease: response to dental pulp stimulation. Hypertension 1997;30:1279-83.

21. Kannel WB, Dannenberg AL, Abbott RD. Unrecognized myorcardial infarction and hypertension: The Framingham Study. Am Heart J 1985;109:581-5

22. Tibblin G, Lindström B. Complaints in subjects with angina pectoris and hypertension. In: Zanchetti A, ed. Neural and Psychological Mechanisms in Cardiovascular Disease. Milan: Il Ponte, 1972:135-9.

23. Melzack R. The McGill Pain Questionnaire: Major properties and scoring methods. Pain 1975;1:277-99.

24. Schobel HP, Handwerker HO, Schmieder RE, Heusser K, Dominiak P, Luft FC. Effects of naloxone on hemodynamic and sympathetic nerve responses to pain in normotensive vs borderline hypertensive men. J Auton Nerv Syst 1998;69:49-55.

25. France C, Stewart K. Parental history of hypertension and enhanced cardiovascular reactivity are associated with decreased pain ratings. Psychophysiology 1995;32:571-8.

26. Al'Absi M, Buchanan T, Lovallo W. Pain perception and cardiovascular responses in men with positive parental history for hypertension. Psychophysiology 1996;33:655-61.

27. Stewart KM, France CR. Resting systolic blood pressure, parental history of hypertension, and sensitivity to noxious stimuli. Pain 1996;68:369-74.

28. Guasti L, Cattaneo R, Daneri A, et al. Endogenous beta-endorphins in hypertension: correlation with 24-hour ambulatory blood pressure. J Am Coll Cardiol 1996;28:1243-8.

29. France C, Ditto B. Risk for high blood pressure and decreased pain perception. Curr Dir Psychol Sci 1996;5:120-5.

30. Bragdon EE, Light KC, Girdler SS, Maixner W. Blood pressure, gender, and parental hypertension are factors in baseline and poststress pain sensitivity in normotensive adults. Int J Behav Med 1997;4:17-38. 


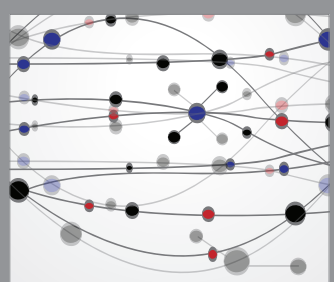

The Scientific World Journal
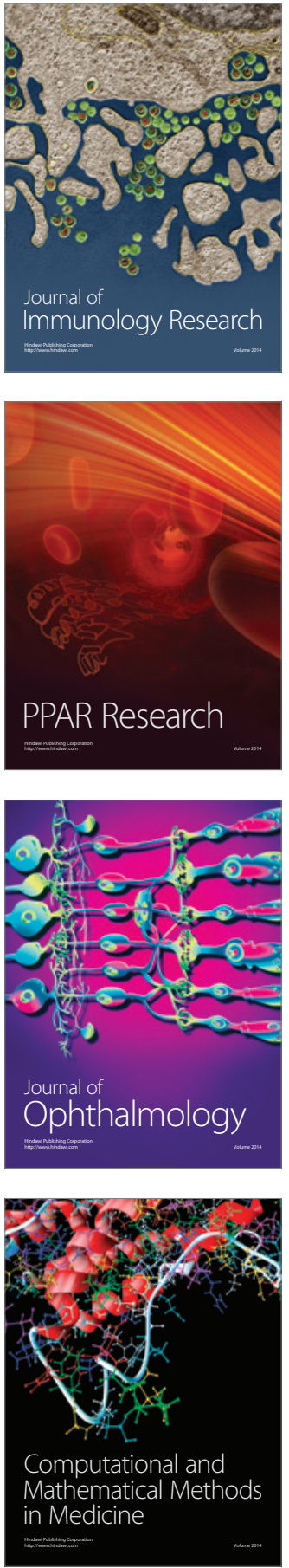

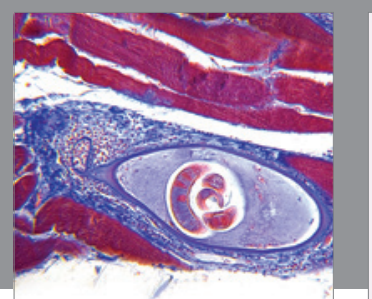

Gastroenterology Research and Practice

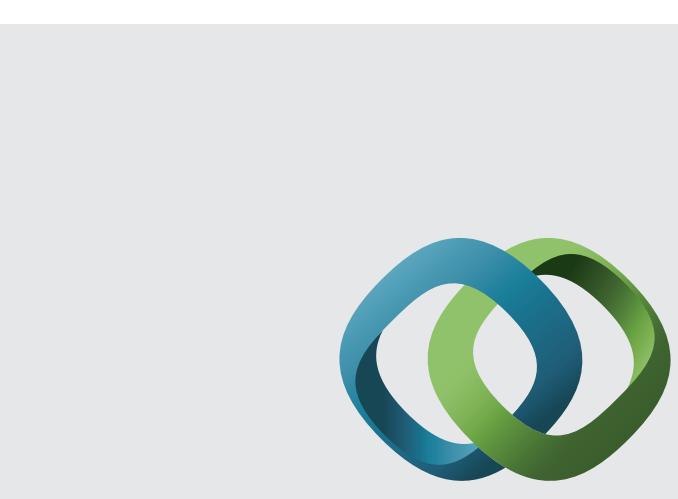

\section{Hindawi}

Submit your manuscripts at

http://www.hindawi.com
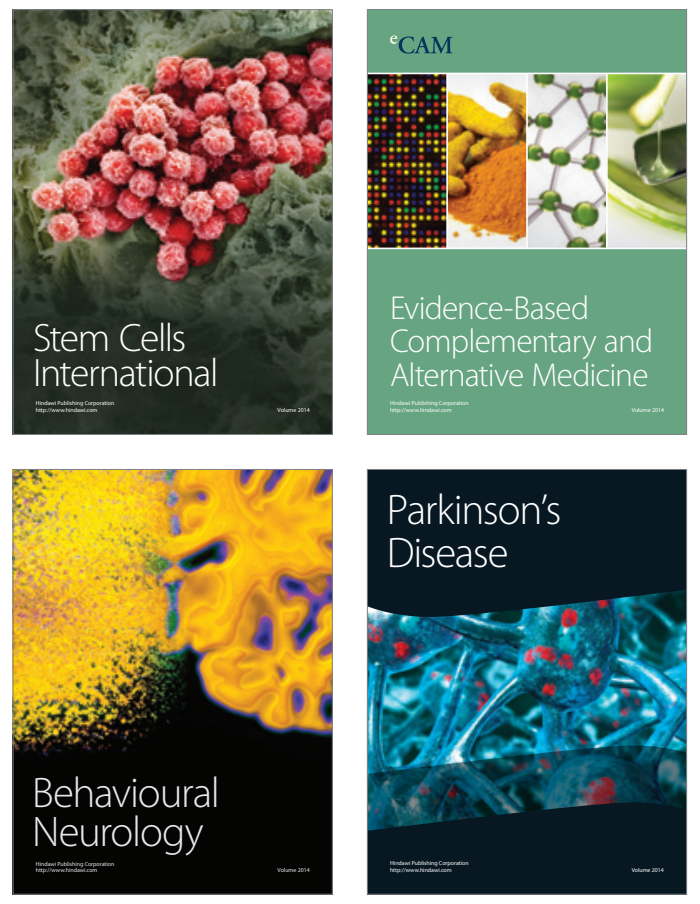
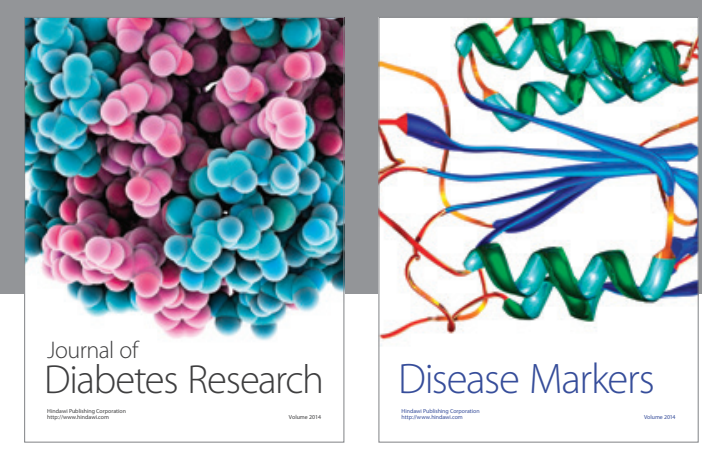

Disease Markers
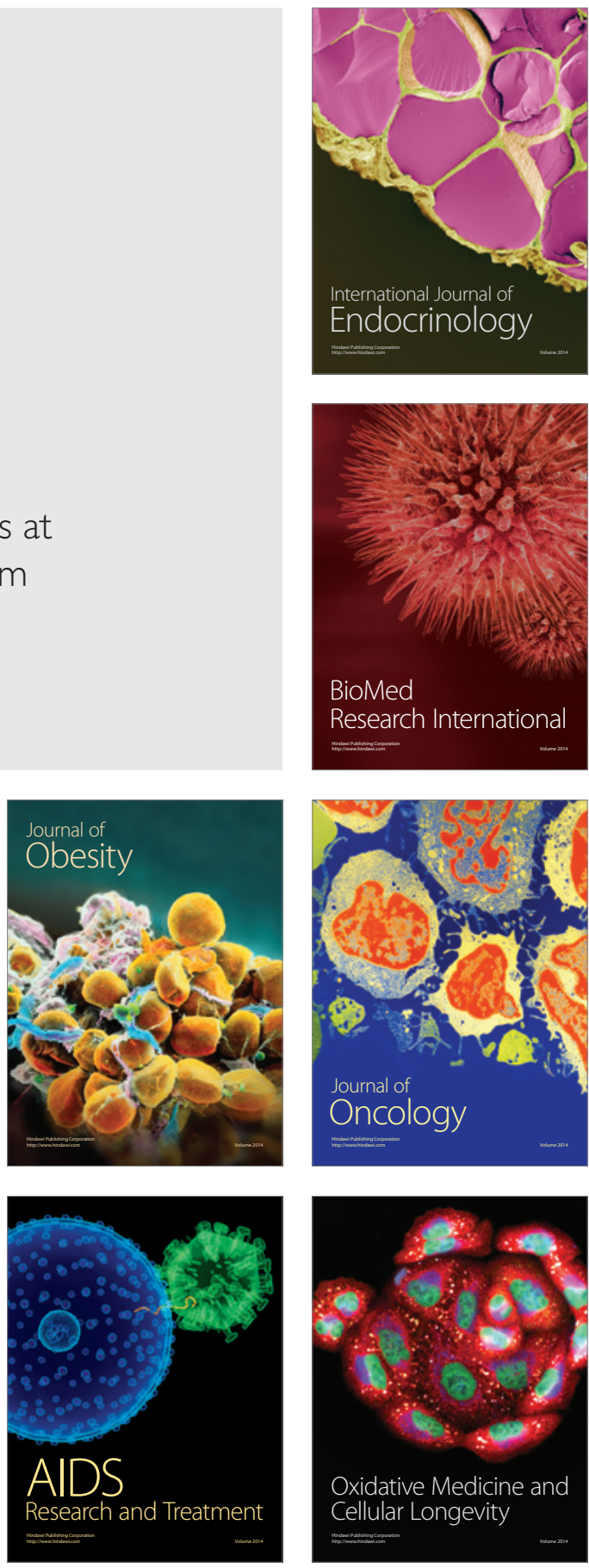